\title{
Survivability of Clostridioides difficile spores in fermented pork summer sausage during refrigerated storage
}

\author{
Genevieve Flock ${ }^{1}(\mathbb{D})$, Hsin-Bai Yin ${ }^{2}$ D , Chi-Hung Chen $^{2}$ (D) , Abraham Joseph Pellissery ${ }^{3}$ and Kumar Venkitanarayanan ${ }^{3}$ (D)
}

1. Combat Capabilities Development Command Soldier Center, Soldier Sustainment Directorate, Combat Feeding Division, Natick 01760, Massachusetts, United States; 2. Department of Agriculture, USDA Agricultural Research Service, Beltsville, Maryland 20705, United States; 3. Department of Animal Science, University of Connecticut, College of Agriculture Health and Natural Resources, Mansfield 06269, Connecticut, United States.

Corresponding author: Kumar Venkitanarayanan, e-mail: kumar.venkitanarayanan@uconn.edu

Co-authors: GF: genevieve.h.flock.civ@army.mil, HY: hsinBai.Yin@usda.gov, CC: chihung.chen@usda.gov, AJP: abraham.pellissery@uconn.edu

Received: 23-08-2021, Accepted: 23-12-2021, Published online: 27-01-2022

doi: www.doi.org/10.14202/vetworld.2022.162-167 How to cite this article: Flock G, Yin H, Chen C, Pellissery AJ, Venkitanarayanan K (2022) Survivability of Clostridioides difficile spores in fermented pork summer sausage during refrigerated storage, Veterinary World, 15(1): 162-167.

\begin{abstract}
Background and Aim: Clostridioides difficile is a spore-forming pathogen that causes serious enteric disease in humans. Strains have been isolated from food animals and meat, including pork, which suggest a potential for foodborne transmission. Pork summer sausage is a popular fermented meat product, which is consumed cooked or cooked to a lower internal temperature due to acidification of the product. The effect of acidity and cooking on the viability of $C$. difficile spores in a fermented meat product has not been determined. Therefore, the aim was to study the survivability of $C$. difficile spores in fermented pork summer sausage.
\end{abstract}

Materials and Methods: Fermented pork sausages were prepared according to a commercial recipe with or without starter culture and $C$. difficile spores followed by fermentation at $37^{\circ} \mathrm{C}$ for $\sim 12 \mathrm{~h}$ under $85 \%$ relative humidity until $\mathrm{pH} 5.0 \mathrm{was}$ reached and further processed as cooked $\left(>57^{\circ} \mathrm{C}\right)$ or uncooked $\left(\leq 57^{\circ} \mathrm{C}\right)$ and stored at $4^{\circ} \mathrm{C}$. C. difficile spores in sausages were enumerated at $1 \mathrm{~h}$ following inoculation and on days $0,1,7,14,21,30,60$, and 90 of storage.

Results: It was observed that $C$. difficile spore viability in control unfermented treatment was significantly different on day 0 from the fermented, fermented cooked, and control unfermented cooked treatments $(\mathrm{p}<0.05)$; however, there was no significant difference among the latter three treatment groups throughout 90 days of storage ( $\mathrm{p}>0.05)$. On day 90 of storage, the unfermented control sausages yielded $\sim 4.0 \log$ colony-forming unit (CFU)/g of $C$. difficile spores compared to $3.5 \log$ $\mathrm{CFU} / \mathrm{g}$ recovered from fermented samples and the unfermented cooked control samples identifying spore viability in all treatment groups.

Conclusion: $C$. difficile spores were found to survive the acidity and cooking of fermented pork summer sausage and storage at $4^{\circ} \mathrm{C}$ for 3 months, thereby highlighting the need for effective intervention strategies to reduce the risk of $C$. difficile contamination in pork products.

Keywords: acidity, Clostridioides difficile, fermented pork sausage, spores.

\section{Introduction}

Clostridioides difficile is a Gram-positive, anaerobic nosocomial pathogen which causes a serious and potentially life-threatening toxin-mediated disease $[1,2]$. The infection is characterized by abdominal pain and diarrhea, leading to more serious clinical manifestations such as colitis and toxic megacolon [3]. Although traditionally regarded as a nosocomial infection, especially in those receiving antimicrobial therapy [4,5], a newer epidemiological trend observed in $C$. difficile incidence is an increase in the number and severity of infections in humans, particularly those involving communities outside the hospital

Copyright: Flock, et al. Open Access. This article is distributed under the terms of the Creative Commons Attribution 4.0 International License (http://creativecommons.org/licenses/by/4.0/), which permits unrestricted use, distribution, and reproduction in any medium, provided you give appropriate credit to the original author(s) and the source, provide a link to the Creative Commons license, and indicate if changes were made. The Creative Commons Public Domain Dedication waiver (http://creativecommons.org/ publicdomain/zero/1.0/) applies to the data made available in this article, unless otherwise stated. environment [6,7]. Further, $C$. difficile infections have been increasingly diagnosed in low-risk individuals who are younger with no history of antibiotic treatment $[8,9]$. Many investigators have reported the occurrence of $C$. difficile in a variety of food animals, and a potential reason attributed to increased reports of human $C$. difficile infections is the rise in isolation rates of the pathogen from animal reservoirs $[10,11]$. C. difficile has been isolated from raw and ready-toeat (RTE) meats such as pork, intended for human consumption at retail stores [12-14]. The detection of genotypically similar and identical $C$. difficile strains implicated from human infections in food animals and foods [15-17] further strengthens the potential role of food as a source of community-associated $C$. difficile infection $[18,19]$. However, additional research is recommended to understand the relationship and potential risk of $C$. difficile in foods and community-associated infections.

C. difficile is a major cause of enteritis in neonatal pigs $[20,21]$, leading to significant mortality 
in suckling piglets and high isolation rates of up to $35 \%$ [22,23]. C. difficile has also been isolated from live adult pigs at rates up to $23 \%$, with high colonization rates in sows around the time of farrowing $[17,24]$. With swine as a potential reservoir of $C$. difficile, contamination of swine carcasses at the time of slaughter could lead to downstream contamination of pork and other RTE pork products. In addition, a survey involving sausage processing plants in Texas and retail meat locations isolated $C$. difficile from $9.5 \%(23 / 243)$ of meat samples and swab samples collected over a 5-year period [25]. Additional prevalence studies in the US found that $62.5 \%$ of RTE pork braunschweiger and (3/15) braised skin and colon RTE pork products tested positive for $C$. difficile [26,27]. Thus, $C$. difficile isolation in live pigs, processing facilities, and retail pork products identifies the potential risk of $C$. difficile contamination in RTE pork products.

Pork summer sausage is a popular fermented meat product in the United States. It can be classified as cooked (internal temperature $>57^{\circ} \mathrm{C}$ ) or uncooked to a lower temperature (internal temperature $\leq 57^{\circ} \mathrm{C}$ ), since acidification due to fermentation is believed to kill any surviving vegetative pathogens in the product $[28,29]$. In addition, the product is typically consumed without an additional cooking step. The starter culture, Pediococcus acidilactici, is commonly used in fermented sausage to produce lactic acid as a by-product of fermentation, which, in turn, lowers the product $\mathrm{pH}$. If $C$. difficile spores could survive the $\mathrm{pH}$ and cooking temperature employed in fermented pork summer sausage, this RTE product could be a potential source of the pathogen.

Since no previous study investigated the viability of $C$. difficile spores in product in the study area, the objective was to determine the viability of $C$. difficile spores in RTE fermented pork summer sausage.

\section{Materials and Methods}

\section{Ethical approval}

Ethical approval was not required for this study because there was no involvement of animal or human subjects.

\section{Study period and location}

The study was conducted from February to September 2015 at the University of Connecticut in Storrs, CT.

\section{Spore preparation}

C. difficile spores were prepared using a previously published protocol with slight modifications [30]. Briefly, single colonies of $C$. difficile ATCC BAA 1805, 1803, and 1053 (human clinical isolates) were separately inoculated into brain heart infusion broth supplemented (BHIS) with 5\% yeast extract (Oxoid, Hampshire, UK) and cultured overnight at $37^{\circ} \mathrm{C}$ under anaerobic conditions. A $150 \mu \mathrm{L}$ aliquot of the overnight culture was gently spread to evenly distribute the culture onto BHIS agar (Oxoid) in 6-well plates and was cultured anaerobically for 7 days at $37^{\circ} \mathrm{C}$ in a Whitley $\mathrm{A} 35$ anaerobic workstation (Microbiology International, Frederick, Maryland, United States) to allow sporulation. After 7 days, spores were harvested from the wells by flooding $2 \mathrm{~mL}$ of ice-cold sterile distilled water $\left(\mathrm{dH}_{2} \mathrm{O}\right)$. The spore suspension was -treated at $60^{\circ} \mathrm{C}$ for $20 \mathrm{~min}$ to kill any vegetative cells and washed 5 times in sterile $\mathrm{dH}_{2} \mathrm{O}$ by centrifuging at $16,000 \mathrm{x} g$ for $5 \mathrm{~min}$. Spore suspensions were visualized under a microscope to ensure $90 \%$ sporulation before storage at $-20^{\circ} \mathrm{C}$.

\section{Sausage preparation and fermentation}

Fermented pork sausages were prepared according to a published protocol $[31,32]$. Pork $(90 \%$ lean $)$ was hand mixed with the addition of sterile $\mathrm{dH}_{2} \mathrm{O}$, salt (2.25\%), summer sausage spice mix (Sausage Maker, Buffalo, New York, United States), sodium erythorbate (Sigma-Aldrich, St. Louis, Missouri, United States), curing salt, and dextrose (Sigma-Aldrich). C. difficile spores (5 log colony-forming unit [CFU]/g of pork batter) and starter culture $P$. acidilactici at $7 \mathrm{log}$ CFU/g (SAGA ${ }^{\mathrm{TM}} 200$ Kerry Ingredients and Flavours, Rochester, Minnesota, United States) were added to ground pork. The ground pork batter was then hand mixed and minced with a manual grinder (Weston, Strongsville, Ohio, United States) using a $3 / 8$ " grinding plate. A sausage formulation, including all ingredients except $P$. acidilactici, was included as an unfermented control. The ground pork mixture was stuffed into synthetic casings (Nojax ${ }^{\circledR}$ Casings 13/16" provided by Viskase, Darien, Illinois, United States) using a jerky gun with a $10 \mathrm{~mm}$ stuffing horn (LEM, West Chester, Ohio, United States). Sausages were fermented at $37^{\circ} \mathrm{C}$ for $\sim 12 \mathrm{~h}$ under $85 \%$ relative humidity $(\mathrm{RH})$ until pH 5.0 was reached. A Caron humidity-controlled incubator (Caron Products, Marietta, Ohio, United States) was utilized for fermentation to maintain $37^{\circ} \mathrm{C}$ and $85 \% \mathrm{RH}$. The fermented group of sausages was fermented to $\mathrm{pH} 5.0$ and one-half were immediately transferred to a drying oven (VWR, Radnor, Pennsylvania, United States) set to $100^{\circ} \mathrm{C}$ for cooking to an internal temperature of $66.5^{\circ} \mathrm{C}$ for $\sim 45 \mathrm{~min}$, where the temperature was continuously monitored using a digital thermocouple (Oakton Instruments, Vernon Hills, Illinois, United States) inserted internally in the sausage. The remaining half of the fermented sausages were uncooked, and all were cooled by transferring to individual gas-impermeable Whirl-Pak ${ }^{\mathrm{TM}}$ bags (Nasco, Fort Atkinson, Wisconsin, United States) and submerging in ice-cold sterile $\mathrm{dH}_{2} \mathrm{O}$ and stored at $4{ }^{\circ} \mathrm{C}$. The control unfermented group of sausages, without starter culture, was also stored at $37^{\circ} \mathrm{C}$ for $\sim 12 \mathrm{~h}$ under $85 \% \mathrm{RH}$, and onehalf were subjected to cooking utilizing the method stated above. The remaining half were uncooked and subsequently cooled and stored in Whirl-Pak ${ }^{\mathrm{TM}}$ bags at $4^{\circ} \mathrm{C}$. 


\section{Bacterial enumeration for sausages}

Three sausage samples from each treatment group were analyzed for $\mathrm{pH}$, water activity $\left(\mathrm{a}_{\mathrm{w}}\right)$, viable $C$. difficile spores, and $P$. acidilactici populations at $1 \mathrm{~h}$ following inoculation and on days $0,1,7$, $14,21,30,60$, and 90 of refrigerated storage. Each sausage was removed from its casing, and both the casing and sausage were together added to a Whirl$\mathrm{Pak}^{\mathrm{TM}}$ bag containing $10 \mathrm{~mL}$ of phosphate-buffered saline (PBS pH 7.0) and subjected to stomaching for $1 \mathrm{~min}$. After stomaching, $1 \mathrm{~mL}$ of the sausage homogenate was pour plated in duplicate with Clostridium difficile moxalactam norfloxacin agar supplemented with $0.1 \%$ sodium taurocholate (CDMNT). The plates were incubated anaerobically at $37^{\circ} \mathrm{C}$ for $48 \mathrm{~h}$. In addition, $1 \mathrm{~mL}$ of the homogenate was added to $9 \mathrm{~mL}$ of CDMNT broth and enriched for $24 \mathrm{~h}$ under anaerobic conditions. Following enrichment, a $5 \mathrm{~mL}$ aliquot of the broth was subjected to alcohol shock by adding $5 \mathrm{~mL}$ of $100 \%$ anhydrous ethanol (Sigma) for $1 \mathrm{~h}$ to eliminate vegetative bacteria. The broth was subsequently subjected to centrifugation at $4000 \times \mathrm{g}$ for $10 \mathrm{~min}$, and the pellet was resuspended in $0.5 \mathrm{~mL}$ of PBS and pour plated with CDMNT agar. The CDMNT agar plates were incubated anaerobically at $37^{\circ} \mathrm{C}$ for $48 \mathrm{~h}$. Moreover, the population of $P$. acidilactici present in each of three sausage samples at each time point was enumerated by plating on de Man, Rogosa, and Sharpe agar (Oxoid) with incubation at $37^{\circ} \mathrm{C}$ for $48 \mathrm{~h}$ [33].

The $\mathrm{pH}$ and $\mathrm{a}_{\mathrm{w}}$ of the fermented pork summer sausages were measured as described by Hristo et al. [34]. Briefly, $\mathrm{pH}$ was determined at $25^{\circ} \mathrm{C}$ by inserting a pre-calibrated $\mathrm{pH}$ meter probe (Thermo Fisher Scientific, Waltham, Massachusetts, United States) directly into three sausage samples from each treatment group by time point. For measuring $\mathrm{a}_{\mathrm{w}}$ at room temperature $\left(25^{\circ} \mathrm{C}\right)$ a calibrated $\mathrm{a}_{\mathrm{w}}$ meter (Rotronic, Hauppauge, New York, United States) was used, and sausage samples from each treatment group were cut into small pieces and placed in a plastic sample cup. The bottom of the cups was completely covered with sausage sample, placed in the $\mathrm{a}_{\mathrm{w}}$ meter, and readings were recorded following humidity and temperature stabilization of the instrument.

\section{Statistical analysis}

All experiments included triplicate samples for each treatment, and the study was repeated 3 times. The experiment was a split-plot design with the whole plot as the original ground pork batter, which was split into two groups with or without starter culture (control unfermented and fermented). These two batter groups were further split into two groups of cooked and uncooked (control unfermented cooked and fermented cooked), making this a split-split-split plot with randomized complete block. The treatment groups, control unfermented, fermented, control unfermented cooked, and fermented cooked, are the independent variables and $C$. difficile spore counts (CFU/g) are the dependent variable. The data were analyzed using the PROC-GLIMMIX procedure of SAS version 9.4 (SAS Institute Inc., Cary, North Carolina, United States), and differences between the means were considered significantly different at $p<0.05$. The fixed effects were the treatment groups and the random effects were considered the treatment group and day of storage interaction. A least significant difference test was used to differentiate the variations $(p<0.05)$ with appropriate corrections for multiple comparisons due to replication, treatment, and time on spore counts.

\section{Results and Discussion}

Results revealed that $C$. difficile spores remained viable under an acidic $\mathrm{pH}$ of 5.0 in fermented pork summer sausage during 3 months of refrigerated storage in all treatment groups. $C$. difficile spore viability in control unfermented treatment was significantly different on day 0 from the fermented, fermented cooked, and control unfermented cooked treatments $(p<0.05)$; however, there was no significant difference among the latter three treatment groups throughout 90 days of storage $(\mathrm{p}>0.05)$ (Figure-1).

On day 90 of storage, the control unfermented sausages yielded $\sim 4.0 \log \mathrm{CFU} / \mathrm{g}$ of $C$. difficile spores compared to $\sim 3.5 \log \mathrm{CFU} / \mathrm{g}$ recovered from fermented samples and the control unfermented cooked samples, identifying spore viability in all treatment groups. P. acidilactici counts in the fermented group remained at $\sim 7.5 \log \mathrm{CFU} / \mathrm{g}$ throughout 90 days of storage, but declined in the fermented cooked group from day 21 , reaching $\sim 2 \log \mathrm{CFU} / \mathrm{g}$ by the end of storage (Figure-2).

The $\mathrm{pH}$ of control unfermented sausage was 5.68 on day 0 and 5.61 on day 90 , with significant variations on days 14 and 60 (Table-1). The $\mathrm{pH}$ of control unfermented cooked sausages was 5.73 on day 0 , which significantly increased to 6.08 by the end of the storage period $(\mathrm{p}<0.05)$, which is consistent with pork characteristics [35]. The $\mathrm{pH}$ of the unfermented sausage groups was consistent with agriculture standards for pork meat [36]. On the other hand, the $\mathrm{pH}$ of fermented sausages was $\sim 4.8$ on day

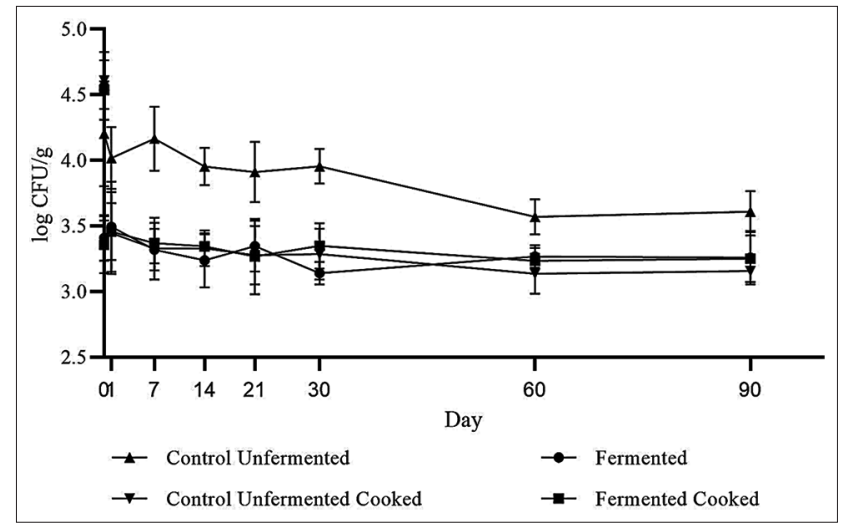

Figure-1: Viability of Clostridioides difficile spores in fermented pork sausage. 
0 , where it increased to 5.04 and $5.31(\mathrm{p}<0.05)$ on day 90 in uncooked and cooked samples, respectively. The significant increase in $\mathrm{pH}$ observed in cooked fermented sausages is consistent with a previous study, where a significant increase in $\mathrm{pH}$ of cooked sausages from 4.75 to 4.84 was observed over 8 weeks of storage [37]. Furthermore, no significant difference in $a_{w}$ was observed within the treatment groups during 90 days of storage, with an average of 0.9 for the cooked treatment groups and 0.93 for the uncooked (fermented only) treatment groups $(\mathrm{p}>0.05)$ (Table-2).

Hypervirulent $C$. difficile isolates have been detected in live pigs, pork sausage manufacturing plants, and retail pork products [17,27]. The United States Department of Agriculture (USDA) guidelines for meat fermentation are based on literature evaluating $\mathrm{pH}$ and temperature parameters for controlling pathogens such as Escherichia coli O157:H7 [29]. A pivotal study on the fate of E. coli $0157: \mathrm{H} 7$ in fermented summer sausage identified that a $5 \log$

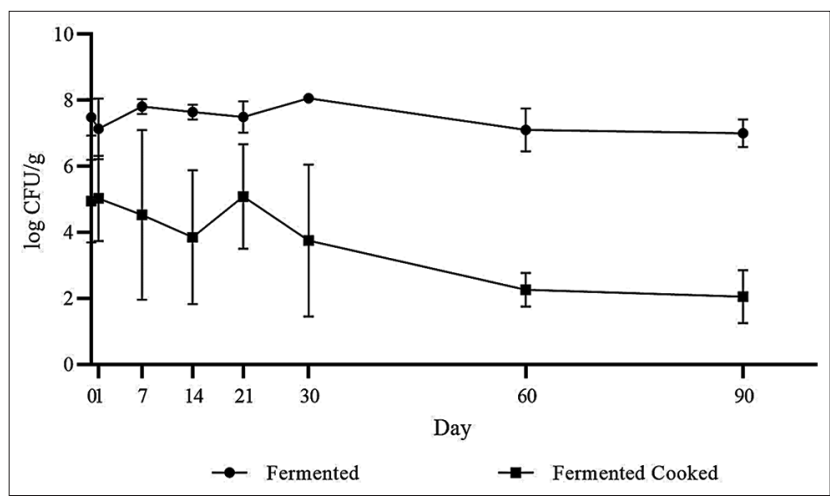

Figure-2: Pediococcus acidilactici populations recovered from fermented pork sausage during storage. reduction in pathogen counts could be achieved with fermentation to a final $\mathrm{pH}$ of 5.0 , followed by heating to an internal temperature of $54^{\circ} \mathrm{C}$ for $30 \mathrm{~min}$, and a $7 \log$ reduction in counts with heating for $60 \mathrm{~min}$ at $54^{\circ} \mathrm{C}$ [28]. However, the results from this study revealed that $C$. difficile remained viable in pork summer sausage despite achieving the aforementioned $\mathrm{pH}$ and even higher cooking temperature. This could be attributed to the differences in the heat and acid resistance between the vegetative cells of $E$. coli $\mathrm{O} 157: \mathrm{H} 7$ and $C$. difficile spores. Although the effect of heat and acidity on the viability of $C$. difficile spores in meat has not been investigated, Rodriguez-Palacios et al. [38] reported that $C$. difficile vegetative cells survived the USDA recommended meat cooking temperature of $71^{\circ} \mathrm{C}$ for $2 \mathrm{~h}$ in phosphate-buffered saline. In addition, C. difficile spores have been found to be more resistant to temperatures between $60^{\circ} \mathrm{C}$ and $75^{\circ} \mathrm{C}$ [39]. Thus, C. difficile spores are expected to survive in the acidity and cooking commonly employed in fermented pork summer sausage, thereby highlighting the need for effective intervention strategies to reduce spore contamination in RTE meat products. Although, $C$. difficile spores require bile salts such as cholate, taurocholate, and glycocholate to stimulate germination [40], spores would unlikely germinate and enter the vegetative state in a food product. Since $C$. difficile spores were found to survive in pork summer sausage during production and storage, there is a possibility that at-risk individuals could be prone to $C$. difficile infection as they are also prone to other pathogens of concern (E. coli 0157:H7, Salmonella enterica spp., and Listeria monocytogenes) in sausage products noted by FSIS [29].

Many RTE meats, including fermented sausages, which are not heated or heated to a lower internal

Table-1: Average pH of fermented and unfermented pork sausage with and without cooking.

\begin{tabular}{lcccc}
\hline Day & Control unfermented & Control unfermented cooked & Fermented & Fermented cooked \\
\hline Day 0 & 5.68 & 5.73 & 4.80 & 4.81 \\
Day 1 & 5.69 & $5.89^{*}$ & $4.92^{*}$ & $5.05^{*}$ \\
Day 7 & 5.73 & $5.94^{*}$ & 4.74 & $5.02^{*}$ \\
Day 14 & $5.81^{*}$ & $5.99^{*}$ & $4.65^{*}$ & $5.06^{*}$ \\
Day 21 & 5.61 & $6.00^{*}$ & 4.72 & $5.15^{*}$ \\
Day 30 & 5.58 & $6.10^{*}$ & 4.72 & $5.19^{*}$ \\
Day 60 & $5.39 *$ & $6.19^{*}$ & 4.73 & $5.32^{*}$ \\
Day 90 & 5.61 & $6.08^{*}$ & $5.04^{*}$ & $5.31^{*}$ \\
\hline
\end{tabular}

*Significant difference between day 0 and sampling day within a treatment group $(p<0.05)$

Table-2: Average water activity of fermented and unfermented pork sausage with and without cooking.

\begin{tabular}{lcccc}
\hline Day & Control unfermented & Control unfermented cooked & Fermented & Fermented cooked \\
\hline Day 0 & 0.936 & 0.910 & 0.938 & 0.898 \\
Day 1 & 0.938 & 0.941 & 0.944 & 0.907 \\
Day 7 & 0.937 & 0.898 & 0.919 & 0.902 \\
Day 14 & 0.935 & 0.908 & 0.919 & 0.883 \\
Day 21 & 0.925 & 0.901 & 0.929 & 0.870 \\
Day 30 & 0.926 & 0.900 & 0.887 & 0.886 \\
Day 60 & 0.925 & 0.912 & 0.930 & 0.908 \\
Day 90 & 0.929 & 0.905 & 0.935 & 0.889 \\
\hline
\end{tabular}

No significant difference within treatment groups ( $p>0.05)$ 
temperature, contain preservatives to control spoilage bacteria and foodborne pathogens. Sodium nitrite is a preservative commonly used to control $C$. botulinum spores, as well as spoilage bacteria in RTE, cured meat $[41,42]$. However, a recent study reported that even vegetative cells of $C$. difficile are resistant to the USDA recommended levels of nitrite (200 ppm) and nitrate $(500 \mathrm{ppm})$ in RTE meat products [43]. The study also noted that the use of both preservatives together did not exert a synergistic effect against C. difficile. It is highlighted that this study was conducted with vegetative $C$. difficile, and spores being more resistant than vegetative cells to antimicrobials. It is logical to conclude that nitrites and nitrates would not kill $C$. difficile spores if present in RTE meat products. The aforementioned results documenting the resistance of $C$. difficile spores to a commonly used preservative in RTE meat, along with our results showing the survival of $C$. difficile spores under a $\mathrm{pH}$ of 5.0 and cooking temperature of $66.5^{\circ} \mathrm{C}$ for $45 \mathrm{~min}$ in fermented sausages, underscore the potential risk of the pathogen in RTE meat.

\section{Conclusion}

Fermentation and cooking $\left(66.5^{\circ} \mathrm{C}\right.$ for $\left.45 \mathrm{~min}\right)$ of fermented pork summer sausage resulted in only marginal reduction in $C$. difficile spores. The $\mathrm{pH}$ of $<5$, fermentation for $12 \mathrm{~h}$, and subsequent cooking to an internal temperature of up to $66.5^{\circ} \mathrm{C}$ did not reduce C. difficile spores in pork summer sausage stored at refrigeration temperature for 3 months $(\mathrm{p}>0.05)$. However, follow-up research to determine the outgrowth potential of $C$. difficile spores during temperature-abuse storage and higher cooking temperatures above $75^{\circ} \mathrm{C}$ during the processing of fermented pork summer sausage is warranted. This study also highlights the need for further research on the potential risk of spore transmission to humans from live pigs, processing facilities, and meat products. As a suggestion for future implementation in meat safety mandates, it is recommended to consider $C$. difficile as a foodborne hazard in minimally cooked and fermented summer sausage products that may potentially contribute to the incidence of community-associated $C$. difficile infections in at-risk and immunocompromised individuals.

\section{Authors' Contributions}

GF and KV: Conceived the study. GF, HY, CC, and AJP: Produced the fermented pork summer sausages and performed enumeration time points. GF: Analyzed data and drafted the manuscript. KV: Main editor of the manuscript. AJP: Assisted in the manuscript editing. All authors have read and approved the final manuscript.

\section{Acknowledgments}

This study did not receive any specific grant from funding agencies in the public, commercial, or not-forprofit sectors. We would like to thank the Department of Animal Science for supporting this research and specifically Dr. Dennis D'Amico for allowing us to borrow critical laboratory equipment. Kind acknowledgment is also given to Dr. Cameron Faustman for consultation on sausage production methodology.

\section{Competing Interests}

The authors declare that they have no competing interests.

\section{Publisher's Note}

Veterinary World remains neutral with regard to jurisdictional claims in published institutional affiliation.

\section{References}

1. Lessa, F.C., Gould, C.V. and McDonald, L.C. (2012) Current status of Clostridium difficile infection epidemiology. Clin. Infect. Dis., 55(2): S65-S70.

2. Mileto, S.J., Jardé, T., Childress, K.O., Jensen, J.L., Rogers, A.P., Kerr, G., Hutton, M.L., Sheedlo, M.J., Bloch, S.C., Shupe, J.A., Horvay, K., Flores, T., Engel, R., Wilkins, S., McMurrick, P.J., Lacy, D.B., Abud, H.E. and Lyras, D. (2020) Clostridioides difficile infection damages colonic stem cells via TcdB, impairing epithelial repair and recovery from disease. Proc. Natl. Acad. Sci. U. S. A., 117(14): 8064-8073.

3. Postma, N., Kiers, D. and Pickkers, P. (2015) The challenge of Clostridium difficile infection: Overview of clinical manifestations, diagnostic tools and therapeutic options. Int. J. Antimicrob. Agents., 46(1): S47-S50.

4. Lessa, F.C., Mu, Y., Bamberg, W.M., Beldavs, Z.G., Dumyati, G.K., Dunn, J.R., Farley, M.M., Holzbauer, S.M., Meek, J.I., Phipps, E.C., Wilson, L.E., Winston, L.G., Cohen, J.A., Limbago, B.M., Fridkin, S.K., Gerding, D.N. and McDonald, L.C. (2015) Burden of Clostridium difficile infection in the United States. N. Engl. J. Med., 372(9): 825-834.

5. De Roo, A.C. and Regenbogen, S.E. (2020) Clostridium difficile infection: An epidemiology update. Clin. Colon Rect. Surg., 33(2): 49-57.

6. Desai, K., Gupta, S.B., Dubberke, E.R., Prabhu, V.S., Browne, C. and Mast, T.C. (2016) Epidemiological and economic burden of Clostridium difficile in the United States: Estimates from a modeling approach. BMC Infect. Dis., 16(1): 1-10.

7. Guh, A.Y., Adkins, S.H., Li, Q., Bulens, S.N., Farley, M.M., Smith, Z., Holzbauer, S.M., Whitten, T., Phipps, E.C., Hancock, E.B., Dumyati, G., Concannon, C., Kainer, M.A., Rue, B., Lyons, C., Olson, D.M., Wilson, L., Perlmutter, R., Winston, L.G., Parker, E., Bamberg, W., Beldavs, Z.G., Ocampo, V., Karlsson, M., Gerding, D.N. and McDonald, L.C. (2017) Risk factors for community-associated Clostridium difficile infection in adults: A case-control study. Open Forum Infect. Dis., 4(4): ofx171.

8. Galdys, A.L., Nelson, J.S., Shutt, K.A., Schlackman, J.L., Pakstis, D.L., Pasculle, A.W., Marsh, J.W., Harrison, L.H. and Curry, S.R. (2014) Prevalence and duration of asymptomatic Clostridium difficile carriage among healthy subjects in Pittsburgh, Pennsylvania. J. Clin. Microbiol., 52(7): 2406-2409

9. Schaeffler, H. and Breitrueck, A. (2018) Clostridium difficile-from colonization to infection. Front. Microbiol., 9: 646.

10. Lim, S.C., Knight, D. and Riley, T.V. (2020) Clostridium difficile and one health. Clin. Microbiol. Infect., 26(7): 857-863.

11. Knetsch, C., Kumar, N., Forster, S., Connor, T., Browne, H., Harmanus, C., Sanders, I.M., Harris, S.R., Turner, L., Morris, T., Perry, M., Miyajima, F., Roberts, P., Pirmohamed, M., Songer, J.G., Weese, J.S., Indra, A., 
Corver, J., Rupnik, M., Wren, B.W., Riley, T.V., Kuijper, E.J. and Lawley, T.D. (2018) Zoonotic transfer of Clostridium difficile harboring antimicrobial resistance between farm animals and humans. J. Clin. Microbiol., 56(3):e01384-e01417.

12. Rodriguez, C., Avesani, V., Van Broeck, J., Taminiau, B., Delmée, M. and Daube, G. (2013) Presence of Clostridium difficile in pigs and cattle intestinal contents and carcass contamination at the slaughterhouse in Belgium. Int. J. Food Microbiol., 166(2): 256-262.

13. Mooyottu, S., Flock, G., Kollanoor-Johny, A., Upadhyaya, I., Jayarao, B. and Venkitanarayanan, K. (2015) Characterization of a multidrug-resistant Clostridium difficile meat isolate. Int. J. Food Microbiol., 192: 111-116.

14. Rupnik, M. and Songer, J.G. (2010) Clostridium difficile: Its potential as a source of foodborne disease. Adv. Food Nutr. Res., 60: 53-66.

15. Rodriguez-Palacios, A., Staempfli, H.R., Duffield, T. and Weese, J.S. (2007) Clostridium difficile in retail ground meat, Canada. Emerg. Infect. Dis., 13(3): 485.

16. Bauer, M.P. and Kuijper, E.J. (2015) Potential sources of Clostridium difficile in human infection. Infect. Dis. Clin. North Am., 29(1): 29-35.

17. Weese, J.S., Avery, B.P., Rousseau, J. and Reid-Smith, R.J. (2009) Detection and enumeration of Clostridium difficile spores in retail beef and pork. Appl. Environ. Microbiol., 75(15): 5009-5011.

18. Warriner, K., Xu, C., Habash, M., Sultan, S. and Weese, S.J. (2017) Dissemination of Clostridium difficile in food and the environment: Significant sources of $C$. difficile communityacquired infection? J. Appl. Microbiol., 122(3): 542-553.

19. Muratoglu, K., Akkaya, E., Hampikyan, H., Bingol, E.B., Cetin, O., Colak, H. (2020) Detection, characterization and antibiotic susceptibility of Clostridioides (Clostridium) difficile in meat products. Food Sci. Anim. Resour., 40(4): 578-587.

20. Knight, D.R., Squire, M.M. and Riley, T.V. (2015) Nationwide surveillance study of Clostridium difficile in Australian neonatal pigs shows high prevalence and heterogeneity of PCR ribotypes. Appl. Environ. Microbiol., 81(1): 119-123.

21. Norén, T., Johansson, K. and Unemo, M. (2014) Clostridium difficile PCR ribotype 046 is common among neonatal pigs and humans in Sweden. Clin. Microbiol. Infect., 20(1): O2-O6.

22. Songer, J.G. and Anderson, M.A. (2006) Clostridium difficile: An important pathogen of food animals. Anaerobe, 12(1): 1-4.

23. Songer, J.G. and Uzal, F.A. (2005) Clostridial enteric infections in pigs. J. Vet. Diagn. Investig., 17(6): 528-536.

24. Thakur, S., Sandfoss, M., Kennedy-Stoskopf, S. and DePerno, C.S. (2011) Detection of Clostridium difficile and Salmonella in feral swine population in North Carolina. $J$. Wildl. Dis., 47(3): 774-776.

25. Harvey, R.B., Norman, K.N., Andrews, K., Norby, B., Hume, M.E., Scanlan, C.M., Hardin, M.D. and Scott, H.M. (2011) Clostridium difficile in retail meat and processing plants in Texas. J. Vet. Diagn. Invest., 23(4): 807-811.

26. Songer, J.G., Trinh, H.T., Killgore, G.E., Thompson, A.D., McDonald, L.C. and Limbago, B.M. (2009) Clostridium difficile in retail meat products, USA, 2007. Emerg. Infect. Dis., 15(5): 819.

27. Wu, Y.C., Chen, C.M., Kuo, C.J., Lee, J.J., Chen, P.C., Chang, Y.C. and Chen, T.H. (2017) Prevalence and molecular characterization of Clostridium difficile isolates from a pig slaughterhouse, pork, and humans in Taiwan. Int. J. Food Microbiol., 242: 37-44.

28. Calicioglu, M., Faith, N.G., Buege, D.R. and Luchansky, J.B. (1997) Viability of Escherichia coli O157: H7 in fermented semidry low-temperature-cooked beef summer sausage. $J$. Food. Prot., 60(10): 1158-1162.

29. USDA. (2013) Sausages and Food Safety 2013. Available from: https://www.fsis.usda.gov/food-safety/safe-foodhandling-and-preparation/meat/sausages-and-food-safety. Accessed 15 Aug 2021.

30. Sorg, J.A., Dineen, S.S. (2009) Laboratory maintenance of Clostridium difficile. Curr. Protoc. Microbiol., 12(1): 9A-1.

31. Vignolo, G., Fontana, C. and Fadda, S. (2010) Semidry and dry fermented sausages. In: Handbook of Meat Processing. p379-398.

32. Baccus-Taylor, G., Glass, K.A., Luchansky, J.B. and Maurer, A.J. (1993) Fate of Listeria monocytogenes and pediococcal starter cultures during the manufacture of chicken summer sausage. Poult. Sci., 72(9): 1772-1778.

33. Casquete, R., Benito, M.J., Martín, A., Ruiz-Moyano, S., Hernández, A. and Córdoba, M.G. (2011) Effect of autochthonous starter cultures in the production of "salchichón", a traditional Iberian dry-fermented sausage, with different ripening processes. LWT Food Sci. Technol., 44(7): 1562-1571.

34. Hristo, D., Fejzulla, F. and Todor, S. (2013) Study on factors $(\mathrm{pH}$, water activity, salt content) affecting the growth of Listeria monocytogenes in raw dried cured sausages. Maced. Vet. Rev., 36(2): 91-95.

35. Brewer, M. and Harbers, C. (1991) Effect of packaging on physical and sensory characteristics of ground pork in longterm frozen storage. J. Food. Sci., 56(3): 627-631.

36. Ministry of Agriculture. (2001) Meat $\mathrm{pH}$ and Pork Quality 2001. Available from: http://www.omafra.gov. on.ca/english/livestock/swine/facts/info_qs_meatph.htm. Retrieved on 15-08-2021.

37. Tremonte, P., Sorrentino, E., Succi, M., Reale, A., Maiorano, G. and Coppola, R. (2005) Shelf life of fresh sausages stored under modified atmospheres. J. Food Prot., 68(12): 2686-2692.

38. Rodriguez-Palacios, A., Reid-Smith, R., Staempfli, H. and Weese, S. (2010) Clostridium difficile survives minimal temperature recommended for cooking ground meats. Anaerobe, 16(5): 540-542.

39. Edwards, A.N., Karim, S.T., Pascual, R.A., Jowhar, L.M., Anderson, S.E. and McBride, S.M. (2016) Chemical and stress resistances of Clostridium difficile spores and vegetative cells. Front. Microbiol., 7: 1698.

40. Sorg, J.A. and Sonenshein, A.L. (2008) Bile salts and glycine as cogerminants for Clostridium difficile spores. $J$. Bacteriol. Res., 190(7): 2505-2512.

41. Xi, Y., Sullivan, G.A., Jackson, A.L., Zhou, G.H. and Sebranek, J.G. (2011) Use of natural antimicrobials to improve the control of Listeria monocytogenes in a cured cooked meat model system. Meat Sci., 88(3): 503-511.

42. Hospital, X.F., Hierro, E., Stringer, S. and Fernández, M. (2016) A study on the toxigenesis by Clostridium botulinum in nitrate and nitrite-reduced dry fermented sausages. Int. J. Food Microbiol., 218: 66-70.

43. Lim, S.C., Foster, N.F. and Riley, T.V. (2015) Susceptibility of Clostridium difficile to the food preservatives sodium nitrite, sodium nitrate and sodium metabisulphite. Anaerobe, 37: 67-71. 